\title{
SIMULTANEOUS DETERMINATION OF SACCHARINE, CAFFEINE, SALICYLIC ACID AND BENZOIC ACID IN DIFFERENT MATRIXES BY SALT AND AIR-ASSISTED HOMOGENEOUS LIQUID-LIQUID EXTRACTION AND HIGH-PERFORMANCE LIQUID CHROMATOGRAPHY
}

\author{
ROUHOLLAH HEYDARI $I^{a, 1^{*}}$, MASOUMEH MOUSAVI ${ }^{b}$ \\ ${ }^{a}$ Razi Herbal Medicines Research Center, Lorestan University of Medical Sciences, PO Box 68149-89468, Khorramabad, Iran \\ ${ }^{b}$ Department of Chemistry, Payame Noor Universtiy, Tehran, Iran
}

\begin{abstract}
Saccharine, caffeine, salicylic acid and benzoic acid were extracted and quantified simultaneously by coupling the salt and air-assisted homogeneous liquidliquid extraction (SAAHLLE) technique with high-performance liquid chromatography (HPLC). Various parameters such as extraction solvent and its volume, salt and its concentration, volume of injected air, vortex time and sample $\mathrm{pH}$ were evaluated and optimized. Analytical parameters of the proposed method were determined under the optimized conditions. The calibration curves showed good linearity in the range of 5-100 $\mu \mathrm{g} / \mathrm{mL}$ for saccharine, caffeine, salicylic acid and benzoic acid. The limit of detection (LOD) values for saccharine, caffeine, salicylic acid and benzoic acid were $0.024,0.013,0.0048 \mathrm{and} 0.0052 \mathrm{ng} / \mathrm{mL}$, respectively. The recoveries were in the range of $88.0-94.0 \%$ with RSD values ranging from 3.8 to $6.8 \%$.
\end{abstract}

Keywords: Homogeneous liquid-liquid extraction, salt and air-assisted, saccharine, caffeine, salicylic acid, benzoic acid, high-performance liquid chromatography

\section{INTRODUCTION}

Acquisition both qualitative and quantitative chemical information about an analyte depends on sample preparation method and analytical instrument. Also, the quality of obtained information related to the matrix in which the analyte of interest is determined. Therefore, choice of appropriate sample preparation technique is an important step in sample analysis. The next step is to select the analytical method and optimize the conditions for analytes extraction.

A drawback of the use of water-immiscible organic solvents in liquidliquid extraction (LLE) is that due to their low dielectric constants, they are not enable to extract the water-soluble compounds that may require extractions at very low or high $\mathrm{pH}$ values. For this reason, attention to more-polar and water-miscible solvents such as acetonitrile, tetrahydrofuran, isopropanol and methanol lead to introduce an efficient extraction method namely salt-assisted homogeneous liquid-liquid extraction (SAHLLE). In SAHLLE method, addition of an inorganic salt into a mixture of water and a water-miscible organic solvent resulting in separation of the organic solvent from the mixture and the formation of a two-phase system ${ }^{1}$. The SAHLLE technique is simple, fast, inexpensive, and results in extracts containing solutes in an organic solvent that can be evaporated and reconstituted into a small volume of suitable solvent for pre-concentration and high-performance liquid chromatography (HPLC) or gas chromatography (GC) analysis ${ }^{2,3}$. Since the extracts in SAHLLE are compatible with analysis instruments, the extract can be injected directly into the chromatographic systems.

Air-assisted solvent extraction (AASX) is a removal technique in treatment of dilute wastewaters which uses a solvent-coated bubble to enhance the contact between organic and aqueous phases. The advantages of this technique than conventional LLE are high solvent to aqueous contact area and ease of phase separation ${ }^{4-7}$.

Recently, we can couple the AASX with other liquid-liquid extraction techniques using appropriate changes in instrumentation ${ }^{8,9}$. Coupling process can leads to increase in extraction efficiency and reduces the extraction time.

Saccharine, caffeine and benzoic acid were quantified using various techniques individually and in combination together in different matrixes. In order to extraction and quantification of these compounds different sample preparation techniques and detection systems were used ${ }^{10-17}$. Also, many methods have been reported for the determination of salicylic acid individually and in combination with other compounds in various matrixes using different analytical methods such as spectrophotometry, luminescence and HPLC ${ }^{18-22}$. In most of these methods samples were prepared using LLE or solid-phase extraction (SPE) techniques. Compared to salting-out extraction method, these methods are time-consuming, expensive and potentially damaging to the environment.

The aim of this study was to develop and validate an analytical procedure for the determination of saccharine, caffeine, salicylic acid and benzoic acid in food, drug and cosmetic products using the salt and air-assisted homogeneous liquid-liquid extraction (SAAHLLE) technique. To the best our knowledge, it is the first SAAHLLE report for the determination of these four analytes simultaneously. The proposed analytical method was optimized, validated and applied to the quantification of these analytes in commercially available food, drug and cosmetic products.

\section{EXPERIMENTAL}

\section{Chemicals and materials}

Saccharin sodium dihydrate, caffeine, benzoic acid, salicylic acid, acetic acid, acetonitrile (HPLC grade), methanol, acetone, tetrahydrofuran (THF), isopropanol, sodium carbonate, ammonium acetate, sodium chloride, sodium sulfate, magnesium sulfate, sodium dihydrogen phosphate, sodium hydroxide and orthophosphoric acid were purchased from Merck Chemical (Darmstadt, Germany). All chemicals were used without further purification. Deionized water was supplied using a Milli-Q system (Millipore, USA).

\section{Chromatographic conditions}

The HPLC system (Shimadzu Corporation, Kyoto, Japan) which consisted of a quaternary pump (LC-10ATvp), UV-Vis detector (SPD-M10Avp), vacuum degasser and system controller (SCL-10Avp) was used. A manual injector with a $10 \mu \mathrm{L}$ sample loop was applied for loading the sample. Class VP-LC workstation was employed to acquire and process chromatographic data. A reversed-phase $\mathrm{C}_{18}$ analytical column (Shim-Pack VP-ODS, $250 \mathrm{~mm} \times$ $4.6 \mathrm{~mm}$ i.d., $5 \mu \mathrm{m}$, Shimadzu, Japan) was used.

The mobile phase consisted of acidic water ( $\mathrm{pH} 3$ with acetic acid) and acetonitrile. Gradient elution was carried out with $10 \%$ acetonitrile for $10 \mathrm{~min}$ and increased up to $50 \%$ within $10 \mathrm{~min}$. Then it returns to initial conditions within $10 \mathrm{~min}$ and to be kept in this ratio for $5 \mathrm{~min}$. Prior usage of the mobile phase, water and acetonitrile were degassed separately using a Millipore vacuum pump. The UV detector was set at $220 \mathrm{~nm}$. Flow rate and column oven were set at $1.0 \mathrm{~mL} \mathrm{~min}^{-1}$ and ambient temperature.

\section{Standard and sample solution preparation}

Standard stock solutions were prepared by dissolving each analyte in methanol with concentration of $100 \mu \mathrm{g} / \mathrm{mL}$. Working standard solutions at different concentrations were prepared freshly by mixing the appropriate volumes of the stock solutions and diluting with deionized water.

Preparation of toothpaste sample

$1 \mathrm{~g}$ of toothpaste sample was transferred to a $15 \mathrm{~mL}$ conical polypropylene centrifuge tube. $10 \mathrm{~mL}$ deionized water was added and mixture sonicated for $30 \mathrm{~min}$ at $25^{\circ} \mathrm{C}$. The mixture was centrifuged and supernatant filtered through $0.45 \mu \mathrm{m}$ syringe filter. Five milliliters of the filtrated solution was mixed with 5 $\mathrm{mL}$ phosphate buffer $(\mathrm{pH} 3)$. This solution was subjected to SAAHLLE. 
Preparation of soft drink samples

Beverage samples were degassed under vacuum followed by sonication. Then $5 \mathrm{~mL}$ of the samples was filtered through $0.45 \mu \mathrm{m}$ syringe filter and mixed with $5 \mathrm{~mL}$ phosphate buffer ( $\mathrm{pH} 3$ ). This solution was subjected to SAAHLLE.

Preparation of tea sample

$1 \mathrm{~g}$ of powdered tea sample was transferred to a $15 \mathrm{~mL}$ conical polypropylene centrifuge tube. $10 \mathrm{~mL}$ deionized water was added and mixture sonicated for $30 \mathrm{~min}$ at $25^{\circ} \mathrm{C}$. The mixture was centrifuged and supernatant filtered through $0.45 \mu \mathrm{m}$ syringe filter. Five milliliters of the filtrated solution was mixed with $5 \mathrm{~mL}$ phosphate buffer ( $\mathrm{pH} 3$ ). This solution was subjected to SAAHLLE.

Salt and air-assisted homogeneous liquid-liquid extraction procedure (SAAHLLE)

$5 \mathrm{~mL}$ of sample or standard solution and $5 \mathrm{~mL}$ phosphate buffer $(\mathrm{pH} 3$ ) were transferred into a $50 \mathrm{~mL}$ conical polypropylene centrifuge tube. Then 2.5 $\mathrm{g}$ of sodium carbonate and $800 \mu \mathrm{L}$ of acetonitrile as extraction solvent were added and then the mixture was vortexed using a vortex mixer (DRAGON LAB MX-S, Beijing, China) at $2500 \mathrm{rpm}$ for $2 \mathrm{~min}$. The cloudy mixture was transferred into a long glass tube (length: $55 \mathrm{~cm}$ and inner diameter: 70 $\mathrm{mm}$ ) and was subjected to aeration process until phase separation occurs and aqueous phase was clear. Then the organic phase by using water injection was moved to the top of the tube. Finally, $10 \mu \mathrm{L}$ of organic phase was withdrawn and injected into the HPLC system for analysis. The schematic diagram of extraction process was described in scheme 1 .

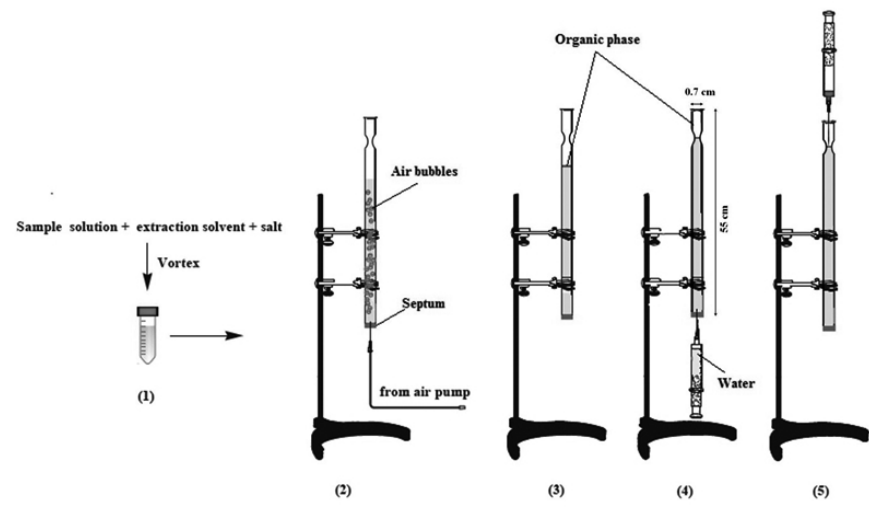

Scheme 1. Schematic diagram of proposed salt and air-assisted homogeneous liquid-liquid extraction (SAAHLLE) procedure. (1) the mixture of sample solution, extraction solvent and salt was mixed using a vortex mixer, (2) the cloudy mixture was transferred to long tube and connected to air pipe from an air pump (3) separation of organic phase by using aeration process, (4) elevating the organic phase by using water injection through the septum in the bottom of tube, (5) removal of $10 \mu \mathrm{L}$ of the collected organic phase in the narrow region of the tube for analysis.

\section{RESULTS AND DISCUSSION}

The performance and extraction efficiency of SAAHLLE are depended to various parameters such as: the solvent type and its volume, salt type and its concentration, sample $\mathrm{pH}$ and volume of injected air which are needed to be investigated and optimized to obtain the optimum values of these parameters.

\section{Optimization of extraction conditions}

Choice of extracting solvent is an important step in most extraction techniques. Several water-miscible organic solvents such as isopropanol, acetonitrile, tetrahydrofuran and their binary mixtures were used as extracting solvent. Similar to previously salt-assisted extraction reports ${ }^{23,24}$, acetonitrile was shown the highest extraction efficiency for all analytes. Therefore, acetonitrile was selected as the extracting solvent.

In the next step, the effect of the extracting solvent volume was investigated by varying its volume from 0.9 to $2.5 \mathrm{~mL}$. As observed from Fig. 1, the peak areas of four analytes increased by increasing of extracting solvent volume up to $1.3 \mathrm{~mL}$ and then decreased. At higher volumes of acetonitrile due to increasing of organic phase volume and dilution of the analytes, peak areas of the analytes were decreased. Thus, based on the obtained results, $1.3 \mathrm{~mL}$ of acetonitrile was selected as the optimum extracting solvent volume for further experiments.

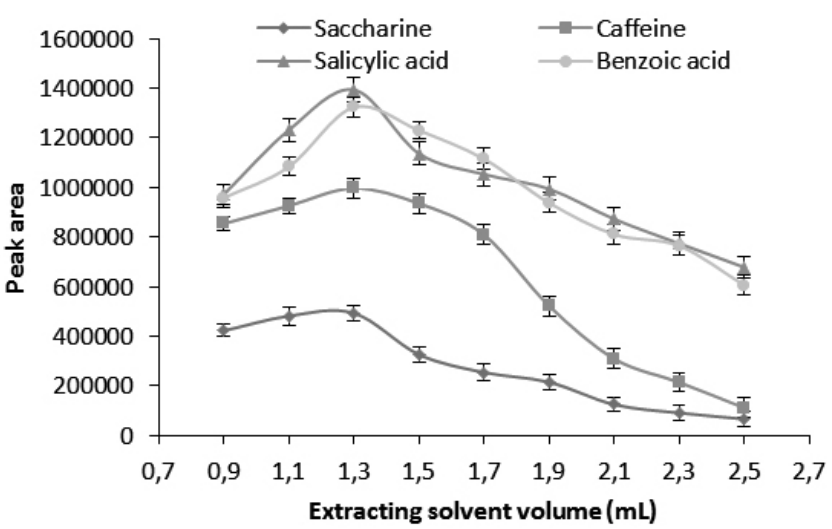

Figure 1. Effect of extracting solvent volume. Extraction conditions: extracting solvent, acetonitrile; sample $\mathrm{pH}$, 3; salt concentration, $30 \% \mathrm{w} / \mathrm{v}$; salt, sodium carbonate; injected air volume, $60 \mathrm{~mL}$; vortex time, $120 \mathrm{~s}$.

The sample $\mathrm{pH}$ has a vital influence on the extraction efficiency of analytes with acidic or basic groups. In the other hand, $\mathrm{pH}$ can be affected on phase separation and volume of recovered organic solvent ${ }^{25,26}$. For these reasons, the effect of sample $\mathrm{pH}$ on the extraction of analytes was studied in the range of 2-10. The obtained results (Fig. 2) were revealed that the extraction efficiency of target analytes was varied in the studied $\mathrm{pH}$ range. Therefore, $\mathrm{pH} 3$ was selected as the best value of $\mathrm{pH}$ for subsequent experiments.

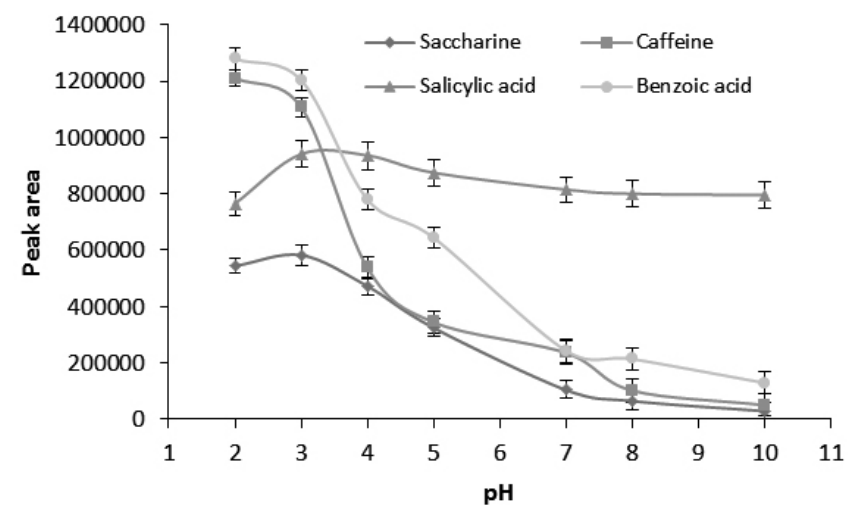

Figure 2. Effect of sample pH. Extraction conditions: extracting solvent, acetonitrile; extracting solvent volume, $1.3 \mathrm{~mL}$; salt concentration, $30 \% \mathrm{w} / \mathrm{v}$; salt, sodium carbonate; injected air volume, $60 \mathrm{~mL}$; vortex time, $120 \mathrm{~s}$.

It has been known that the addition of an inorganic salt into a mixture of water and a water-miscible organic solvent leads to a two-phase system. Also, salting-out effect can be used to enhance extraction efficiency of target analytes into the extracting solvent and sample headspace in most of extraction techniques. This behavior was attributed to decrease of analytes solubility in aqueous phase in presence of salt. Type of salt and its concentration are important parameters in SAHLLE technique. Various salts such as sodium carbonate, ammonium acetate, sodium chloride, sodium sulfate and magnesium sulfate with different concentrations were investigated. Among these salts, sodium carbonate was shown maximum extraction efficiency for four analytes. Therefore, different concentrations of sodium carbonate were used in the range of 20 to $35 \% \mathrm{w} / \mathrm{v}$. As can be observed from results in Fig. 3, 30\% w/v was selected as the optimum salt concentration for subsequent experiments. 


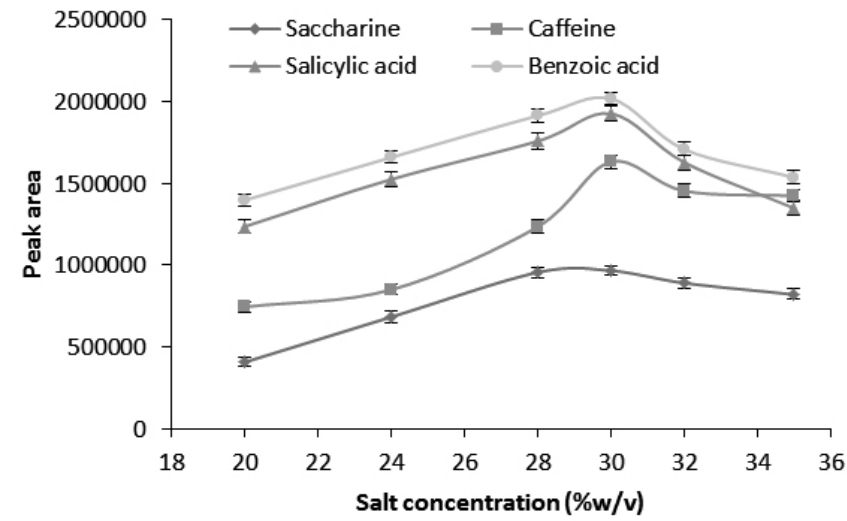

Figure 3. Effect of salt concentration. Extraction conditions: extracting solvent, acetonitrile; extracting solvent volume, $1.3 \mathrm{~mL}$; sample $\mathrm{pH}, 3$; salt, sodium carbonate; injected air volume, $60 \mathrm{~mL}$; vortex time, $120 \mathrm{~s}$.

The effect of injected air volume on the extraction efficiency of analytes was considered in the range of 0 to $90 \mathrm{~mL}$. Air injection leads to sample turbulence and increases the contact surface between the analytes and extracting solvent. Because the density of the extracting solvent is lower than aqueous phase, extracting solvent was collected above the sample solution. Consequently, air bubbles motion to the top of the long tube results to accelerate in phase separation and analytes transfer from aqueous phase to organic phase. The peak area of four analytes increased with the increasing injected air volume and then level off (Fig. 4). Thus, based on the obtained results $60 \mathrm{~mL}$ was selected as the optimum air volume for further experiments.

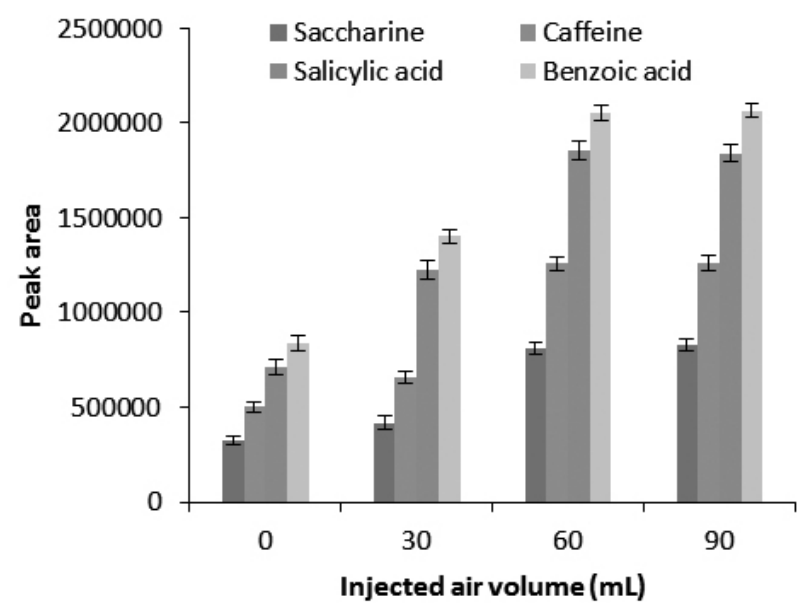

Figure 4. Effect of injected air volume. Extraction conditions: extracting solvent, acetonitrile; extracting solvent volume, $1.3 \mathrm{~mL}$; sample $\mathrm{pH}$, 3; salt concentration, $30 \% \mathrm{w} / \mathrm{v}$; salt, sodium carbonate; vortex time, $120 \mathrm{~s}$.

In order to increase contact surface between analytes and extracting solvent, sample was shaken vigorously using a vortex device. Effect of vortex time on the extraction efficiency was evaluated in the range of 30 to $300 \mathrm{~s}$. Fig. 5 shows peak area of all analytes increased with the increasing vortex time up to $120 \mathrm{~s}$ and then reduced or remained constant. Therefore, $120 \mathrm{~s}$ was choice as the optimum vortex time.

\section{Method evaluation}

The developed SAAHLLE method was validated in terms of linearity, limit of detection (LOD), limit of quantitation (LOQ), precision, accuracy and selectivity. The analytical figures of merit of the proposed analytical technique are summarized in Table 1.

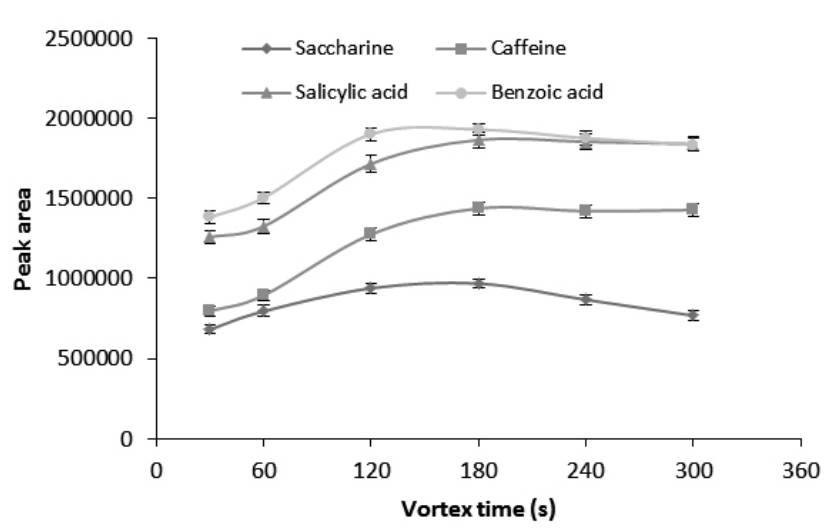

Figure 5. Effect of vortex time. Extraction conditions: extracting solvent, acetonitrile; extracting solvent volume, $1.3 \mathrm{~mL}$; sample $\mathrm{pH}$, 3; salt concentration, $30 \% \mathrm{w} / \mathrm{v}$; salt, sodium carbonate; injected air volume, $60 \mathrm{~mL}$.

Table 1. Some of analytical parameters for the proposed method.

\begin{tabular}{|c|c|c|c|c|c|}
\hline Analyte & $\begin{array}{c}\mathrm{LOD} \\
(\mathrm{ng} / \mathrm{mL})\end{array}$ & $\begin{array}{c}\mathrm{LOQ} \\
(\mathrm{ng} / \mathrm{mL})\end{array}$ & $\mathrm{R}^{2}$ & Slope & $\begin{array}{c}\text { Linear } \\
\text { range } \\
(\mu \mathrm{g} / \mathrm{mL})\end{array}$ \\
\hline Saccharine & 0.024 & 0.079 & 0.9978 & 40579 & $1.0-50.0$ \\
\hline Caffeine & 0.013 & 0.042 & 0.9990 & 58685 & $1.0-50.0$ \\
\hline $\begin{array}{c}\text { Salicylic } \\
\text { acid }\end{array}$ & 0.0048 & 0.015 & 0.9982 & 97028 & $1.0-50.0$ \\
\hline $\begin{array}{c}\text { Benzoic } \\
\text { acid }\end{array}$ & 0.0052 & 0.017 & 0.9969 & 100318 & $1.0-50.0$ \\
\hline
\end{tabular}

Precision and accuracy data were obtained using spiked real samples containing each analytes in three concentration levels. Relative standard deviation (RSD) values for saccharine, caffeine, salicylic acid and benzoic acid were in the range of 3.8-6.5, 4.3-6.8, 3.8-6.8 and 4.7-6.2\%, respectively (Table 2 ). In order to validate the method accuracy, the recovery tests were performed by the analysis of the samples spiked with three different concentrations of each analytes. Relative recovery values for saccharine, caffeine, salicylic acid and benzoic acid were in the range of 88-92, 89-91, 90-94 and 91-92\%, respectively.

Fig. 6 shows the chromatograms of blank and analytes mixture which obtained under the optimized extraction conditions. Comparison of chromatograms of analytes mixture before and after extraction indicate analytes were concentrated using the proposed method.

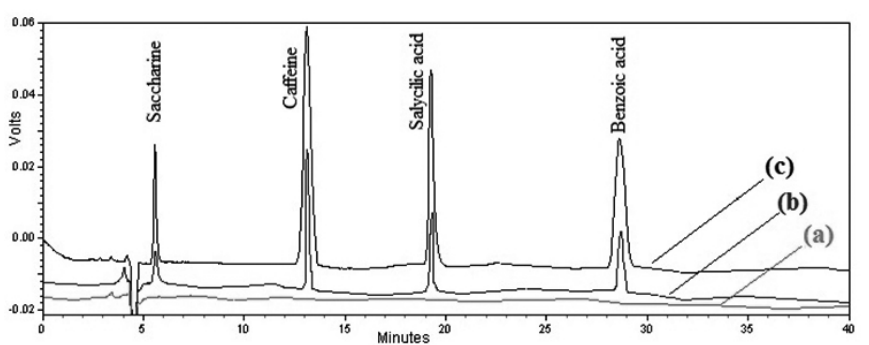

Figure 6. Chromatograms of blank (a), standard solution before extraction (b) and standard solution after extraction using the proposed method under the optimized conditions (c).

To evaluate the analytical performance, the proposed method was employed for the determination of four analytes in several samples with different matrixes including two soft drink, toothpaste and salicylic acid topical solution samples. The results in Table 3 indicate that this method can be successfully applied for determination of target analytes in the studied matrixes. 
Table 2. Precision and accuracy data for the proposed method.

\begin{tabular}{|c|c|c|c|c|}
\hline \multirow{3}{*}{ Analyte } & \multirow{2}{*}{ Concentration $(\mu \mathrm{g} / \mathrm{mL})$} & \multicolumn{2}{|c|}{ RSD $(\%)$} & \multirow{2}{*}{ Recovery $(\%)(\mathrm{n}=3)$} \\
\cline { 2 - 5 } & & Within day $(\mathrm{n}=5)$ & Between days $(\mathrm{n}=15)$ & $88 \pm 2.0$ \\
\hline \multirow{3}{*}{ Saccharine } & 5 & 4.4 & 6.5 & $92 \pm 1.5$ \\
\cline { 2 - 5 } & 10 & 4.5 & 5.9 & $90.5 \pm 2.0$ \\
\hline \multirow{3}{*}{ Caffeine } & 20 & 3.8 & 6.3 & $90 \pm 1.7$ \\
\cline { 2 - 5 } & 5 & & & $89 \pm 2.0$ \\
\hline \multirow{3}{*}{ Salicylic acid } & 10 & 5.2 & 6.8 & $91 \pm 2.1$ \\
\cline { 2 - 5 } & 20 & 4.3 & 5.6 & $90 \pm 2.0$ \\
\hline & 5 & 5.1 & 5.5 & $94 \pm 1.8$ \\
\hline \multirow{3}{*}{ Benzoic acid } & 10 & 3.8 & 6.8 & $90 \pm 2.0$ \\
\cline { 2 - 5 } & 20 & 3.8 & 4.6 & $92 \pm 1.6$ \\
\hline & & & & $91 \pm 2.0$ \\
\hline
\end{tabular}

Table 3. The results of analyzed real samples using the proposed method.

\begin{tabular}{|c|c|c|c|c|c|c|c|c|}
\hline \multirow{2}{*}{ Sample } & \multicolumn{2}{|c|}{ Saccharin $(\mathrm{mg} / \mathrm{g})$} & \multicolumn{2}{c|}{ Caffeine $(\mu \mathrm{g} / \mathrm{mL})$} & \multicolumn{2}{c|}{ Salicylic acid $(\mathrm{g} / \mathrm{mL})$} & \multicolumn{2}{c|}{ Benzoic acid $(\mu \mathrm{g} / \mathrm{mL})$} \\
\cline { 2 - 9 } & $\begin{array}{c}\text { Labeled } \\
\text { conc. }\end{array}$ & $\begin{array}{c}\text { Obtained } \\
\text { conc. }\end{array}$ & $\begin{array}{c}\text { Labeled } \\
\text { conc. }\end{array}$ & $\begin{array}{c}\text { Obtained } \\
\text { conc. }\end{array}$ & $\begin{array}{c}\text { Labeled } \\
\text { conc. }\end{array}$ & $\begin{array}{c}\text { Obtained } \\
\text { conc. }\end{array}$ & $\begin{array}{c}\text { Labeled } \\
\text { conc. }\end{array}$ & $\begin{array}{c}\text { Obtained } \\
\text { conc. }\end{array}$ \\
\hline Toothpaste & 100 & 90.0 & -- & -- & -- & -- & -- & -- \\
\hline Soft drink (A) & -- & -- & 100 & 95.0 & -- & -- & 150 & 141 \\
\hline Soft drink (B) & -- & -- & 100 & 93 & -- & -- & 150 & 155 \\
\hline $\begin{array}{c}\text { Salicylic acid topical } \\
\text { solution }\end{array}$ & -- & -- & -- & -- & 0.167 & 0.158 & -- & -- \\
\hline
\end{tabular}

Table 4. Comparison of analytical parameters of the proposed method with several reported methods.

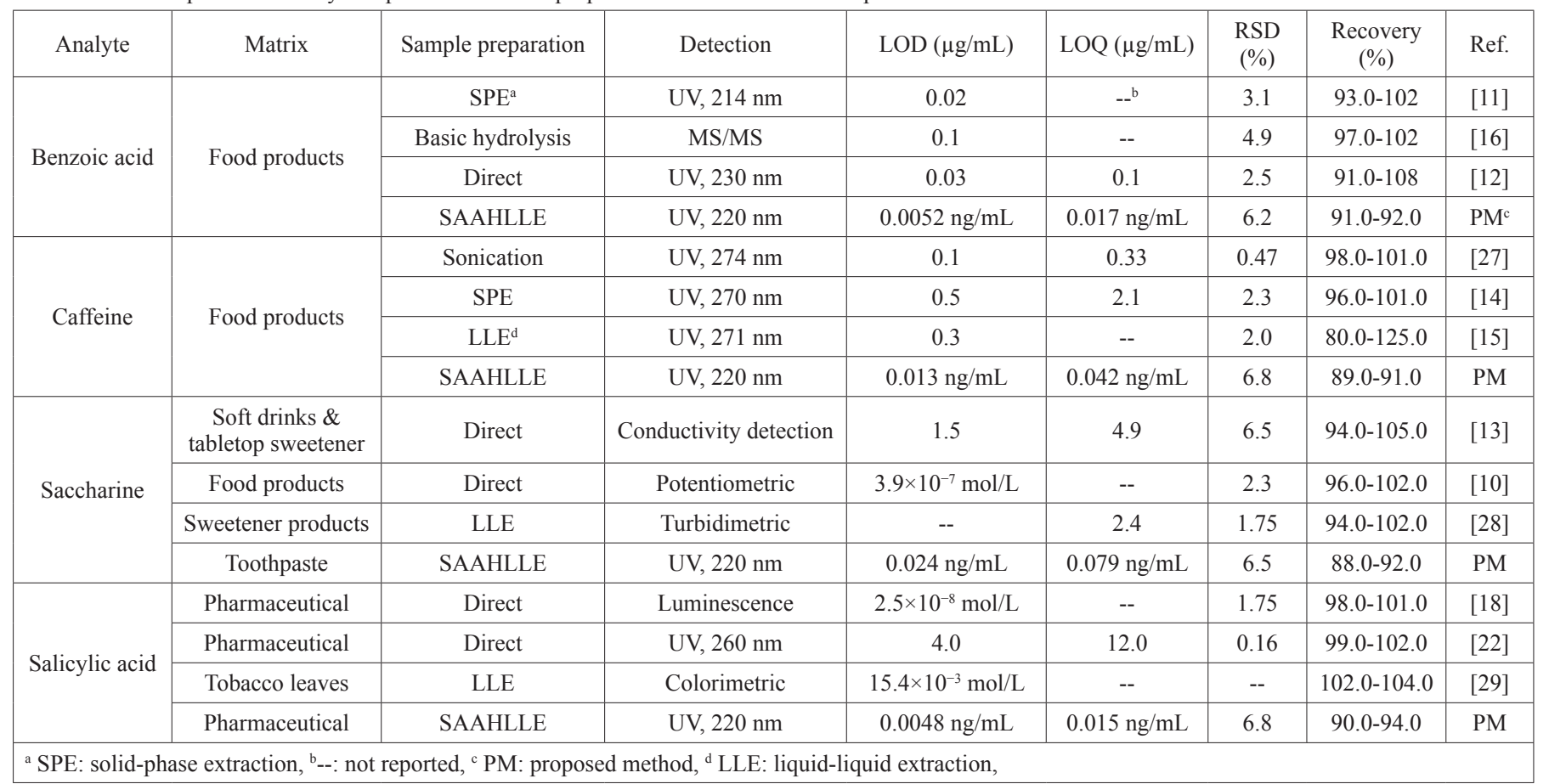


The analytical parameters of the proposed method were compared with those of several reported methods in the literature (Table 4). The results showed that most of these parameters were improved by use of the SAAHLLE method.

\section{CONCLUSION}

In the present work, a simple analytical procedure for the simultaneous determination of four analytes including saccharin, caffeine, salicylic acid and benzoic acid in food, drug and cosmetic samples using SAAHLLE and HPLC was developed. Experimental parameters which can influenced the analytical signals of these analytes were investigated and optimized. Compared to other reported methods, the proposed method offers several advantages such as simplicity, low cost and appropriate performance in real samples analysis. In this study acetonitrile was used as the extraction solvent which it is compatible with various analysis instruments. Consequently, the proposed method will be compatible with different instruments for sample analysis.

\section{ACKNOWLEDGEMENT}

The authors gratefully acknowledge the support of Razi Herbal Medicines Research Center, Lorestan University of Medical Sciences.

\section{REFERENCES}

1. R. Rezaeepour, R. Heydari, A. Ismaili, Anal. Methods. 7, 3253, (2015)

2. R. S. Razmara, A. Daneshfar, R. Sahrai, J. Ind. Eng. Chem. 17, 533 (2011)

3. F. J. Zhao, H. Tang, Q. H. Zhang, J. Yang, A. K. Davey, J. P. Wang, J. Chromatogr. B. 881-882, 119, (2012)

4. H. M. Tarkan, J. A. Finch, Miner. Eng. 18, 83, (2005)

5. H. M. Tarkan, J. A. Finch, Colloid Sur. A. 264, 126, (2005)

6. P. C. Lee, C. W. Li, S. S. Chen, C. H. Chiu, Separ. Sci. Technol. 44, 3911 (2009)

7. C. W. Li, Y. M. Chen, S. T. Hsiao, Chemosphere. 71, 51, (2008)

8. M. Hosseini, R. Heydari, M. Alimoradi, Talanta. 130, 171, (2014)
9. R. Heydari, S. Zarabi, Anal. Methods. 6, 8469, (2014)

10. A. O. Santini, S. C. Lemos, H. R. Pezza, J. Carloni-Filho, L. Pezza, Microchem. J. 90, 124, (2008)

11. F. Han, Y. Z. He, L. Li, G. N. Fu, H. Y. Xie, W. E. Gan, Anal. Chim. Acta. 618, 79, (2008)

12. X. Zhang, S. Xu, Y. Sun, Y. Wang, C. Wang, Chromatographia. 73, 1217 , (2011)

13. A. B. Bergamo, J. A. Fracassi da Silva, D. P. de Jesus, Food Chem. 124, 1714, (2011)

14. E. Rudolph, A. Färbinger, J. König, Food Addit. Contam. A. 29, 1849, (2012)

15. Z. Xia, Y. Ni, S. Kokot, Food Chem. 141, 4087, (2013)

16. Y. Chen, H. Luo, X. Guo, Y. Xian, D. Luo, Y. Wu, Anal. Methods. 6, 4803, (2014)

17. M. Grembecka, P. Baran, A. Blazewicz, Z. Fijalek, P. Szefer, Eur. Food Res. Technol. 238, 357, (2014)

18. M. M. Karim, S. M. Alam, S. H. Lee, Luminescence. 23, 417, (2008)

19. H. Parham, N. Rahbar, J. Pharm. Biomed. Anal. 50, 58, (2009)

20. M. R. Payán, M. A. Bello López, R. Fernández-Torres, J. L. Pérez Bernal, M. C. Mochón, Anal. Chim. Acta. 653, 184, (2009)

21. J. A. Murillo Pulgarín, A. A. Molina, I. S. F. Robles, Spectrochim. Acta A. 79, 909, (2011)

22. R. M. Youssef, M. A. Korany, M. A. Afify, Anal. Methods. 6, 3410, (2014)

23. T. Li, L. Zhang, L. Tong, Q. Liao, Biomed. Chromatogr. 28, 648, (2014)

24. A. Koltsakidou, C. K. Zacharis, K. Fytianos, J. Chromatogr. A. 1377, 46, (2015)

25. C. E. Matkovich, Anal. Chem. 45, 1915, (1973)

26. T. Zhigang, Z. Rongqi, D. Zhanting, J. Chem. Technol. Biotechnol. 76, $757,(2001)$

27. P. D. Tzanavaras, D. G. Themelis, Anal. Chim. Acta. 581, 89, (2007)

28. C. B. Mendes, E. P. Laignier, M. R. P. L. Brigagão, P. O. Luccas, C. R. T. Tarley, Chem. Pap. 64, 285, (2010)

29. P. J. Tseng, C. Y. Wang, T. Y. Huang, Y. Y. Chuang, S. F. Fub, Y. W. Lin, Anal. Methods. 6, 1759, (2014) 